\title{
LA GESTION DE LA DIPUTACION DE PALENCIA DURANTE LA DICTADURA DE PRIMO DE RIVERA *
}

\author{
POR \\ EnRique Orduña Rebollo
}

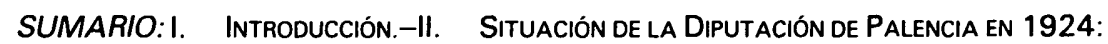
A) Servicios de Beneficencia y Asistencia Social; B) Carreteras; C) Comunicaciones; D) Otros aspectos de la gestión provincial en 1924.-III. GESTIÓN Y ACTIVIDAD DE LA Diputación de Palencia desde 1930 a 1931: A) Instituto de Higiene; B) Desarrollo agrario y repoblación forestal; C) El ferrocarril Palencia-Guardo; D) Caminos vecinales.-IV. La Hacienda Provincial de Palencia: A) La Hacienda Provincial (1920-1924); B) La Hacienda desde el Estatuto Provincial; C) El Banco de Crédito Local y la Diputación.
\end{abstract}

\section{INTRODUCCION}

En diversas ocasiones hemos abordado la problemática local referida al período de la dictadura de don Miguel Primo de Rivera, aunque siempre la tratamos con criterios generalistas, analizando la cuestión desde la perspectiva de los Estatutos Municipal y Provincial, sin descender a casos concretos ni a indagar lo que realmente - sucedió, cuando en provincias y municipios se hizo la aplicación práctica de la normativa dictatorial de régimen local.

El II Congreso de Historia de Palencia es una ocasión que no podemos desaprovechar para profundizar en un caso concreto de la administración provincial en esta coyuntura de la anfitriona Diputación palentina.

En el ámbito de la ponencia del profesor Palomares quedan considerados los factores institucionales y estructurales, que hacen innecesaria cualquier insistencia sobre el particular y a los cuales nos remitiremos en este trabajo. Por ello, el objetivo del mismo será estudiar diversos aspectos de la gestión de la Diputación, tales como presupuestos, beneficencia, obras y servicios, carreteras y caminos.

También es preciso afirmar una vez más que el motor de la reforma local, don José Calvo Sotelo, albergaba el manifiesto propósito de convertir en realidad los fallidos proyectos de régimen local de Maura de 1903 y 1907, con algunas rectificaciones y modificaciones, a través de los Estatutos Municipal y Provincial, los cuales contenían un reconocido perfeccionismo técnico y marcaron

- Trabajo presentado al 2..$^{\circ}$ Congreso de Historia de Palencia, 29 de abril de 1989, organizado por la excelentísima Diputación.Provincial de Palencia. 
un impacto político decisivo en la Administración local española de la época y tiempos posteriores. Lamentablemente el entorno político, carente de libertades públicas, les hizo en gran medida inoperantes. Maura no concebía sus proyectos de ley al margen de un sistema democrático y fuera de un contexto de gran autonomía.

Al pronunciarse el general Primo de Rivera en septiembre de 1923, no parece que la Diputación Provincial de Palencia resultase afectada su gestión, según se desprende al consultar los libros de actas del Pleno y de la Comisión Permanente. La actividad normal continúa, y tras la sesión plenaria del día 3 de agosto de 1923, dentro aún de la legalidad constitucional, en la que se produjo la elección de nuevo presidente, recaída en don José Néstar Barrio, así como la de vicepresidentes y secretarios, renovados según la ley provincial de 1882, no vuelve a reunirse el Pleno de la Diputación hasta el día 2 de noviembre del mismo año, con idéntica composición, como señala Palomares. Respecto a la Comisión Permanente Provincial tampoco se detectan, en principio, novedades y alteraciones excepcionales. Limitándose a cumplir los trámites que ordenaba el Directorio.

La ausencia de impacto inmediato en la Comisión Permanente Provincial se comprueba al revisar su libro de actas, pues a lo largo de las sesiones del mes de septiembre no existen ni siquiera alusiones al nuevo gobierno. A la del día 14 de septiembre, presidida por el señor Arija García, no asiste el señor Herrero Abia, sin excusar su ausencia, situación que se repetirá en las siguientes sesiones, pero más adelante se reincorporará a la Comisión, e incluso presidió alguna reunión.

Los asuntos tratados el 14 de septiembre se refieren a las cuentas de los Ayuntamientos de Capillas y Valoria del Alcor. Informes al Gobierno civil sobre asuntos de trámite, junto con un telegrama al señor Presidente del Consejo de Ministros protestando contra los actos separatistas de Barcelona. Nada más, media hora de sesión según el libro de actas (1).

Al día siguiente, 15 de septiembre, vuelve a reunirse la Comisión para aprobar el balance del mes de agosto e informes al gobernador sobre diversos recursos de alzada, tras lo cual se levantó la sesión. Hasta el día 21 no vuelve a reunirse la Comisión, y en la sesión, presidida por el señor Martínez de Azcoitia Rodríguez, se aprueban cuentas municipales y se evacuan informes al gobernador. A la siguiente reunión del día 22 concurre el jefe administrativo militar, pero sólo hasta que se trata el primer punto del orden del día,

(1) Véase Archivo de la Diputación de Palencia Libro. de Actas (ADPLA). Comisión Permanente, sesión del 14 de septiembre de 1923, folios 70-74. 
referente a la determinación de los precios medios de cada artículo, que servía de base a la administración militar para liquidar los suministros hechos en el mes de agosto, de acuerdo con la Instrucción de 9 de agosto de 1877 y Real Decreto de 1 de diciembre de 1917. Tras lo cual abandonó la sala el referido jefe militar señor Canals, y continuó la sesión, estudiando la distribución de fondos, informes al gobernador, cuentas carcelarias y personal (2). El escollo más complicado para la Diputación palentina se presentó cuando el Directorio ordenó la formación de un presupuesto extraordinario al objeto de saldar los débitos de la Diputación con el Estado por diversos conceptos, gastos contraídos según la Ley de Autorizaciones de 3 de mayo de 1917. Tras diversas alegaciones y gestiones en Madrid, donde también reivindicaron protagonismo en la futura organización regional, fueron rechazadas las pretensiones de posponer la elaboración del presupuesto extraordinario hasta enero de 1924, consiguiendo solamente quince días de prórroga para suspender el procedimiento de apremio por parte de la Hacienda Pública.

Además, publicada en el Boletín Oficial de la Provincia del 30 de octubre la convocatoria para reunir el Pleno el día 2 de noviembre, ésta no reunía las condiciones señaladas por la Ley Provincial de 1882, aún en vigor, que preveía en su artículo 62 un plazo mínimo de ocho días entre la aparición en el BOP de dicha convocatoria y la celebración del Pleno. Ante esta irregularidad y la posible ilegalidad en que podía incurrir la Corporación, diversos diputados manifestaron en la sesión su disconformidad (Salvador Zurita, Nájera de la Guerra y Santos Revuelta). Ante su actitud, el Presidente (Néstar Barrio) argumentó:

"Que no se trata de un periodo normal, sino que esta sesión se celebra por circunstancias especiales y en virtud de mandato de la superioridad en que se ordena, que sin pretexto alguno la Corporación formara y aprobara el presupuesto para atender a los descubiertos que han motivado el apremio de la Hacienda» (3).

Hicieron constar los tres diputados su voto en contra para salvar las posibles responsabilidades en que pudiera incurrir la Diputación

(2) Véase Archivo de la Diputación de Palencia Libro de Actas (ADPLA). Comisión Permanente, sesión del 22 de septiembre de .1923, folio 73.

(3) Véase Archivo de la Diputación de Palencia Libro de Actas (ADPLA). Pleno, Diputación Provincial de Palencia. Año 1923. Sesión de 2 de septiembre de 1923, folio 27 vuelto. Hay que tener en cuenta el permanente endeudamiento de diputaciones $y$ ayuntamientos y los precarios recursos económicos de que disponían. 
por la sesión celebrada, que a su juicio resultaba nula, pero a continuación manifestaron usu acatamiento a las disposiciones de la autoridad constituida» (4). Tras lo cual se dio lectura al proyecto de presupuesto extraordinario, resultando un superávit de $11.683,25$ pesetas. Los ingresos estaban constituidos principalmente por el capítulo XI, «Resultas» (274.405,50 pesetas), y comprendía los descubiertos que diversos ayuntamientos tenían con la Diputación Provincial por cuotas de contingente provincial, segunda enseñanza y caminos vecinales de ejercicios anteriores a 1923-1924. Obedecía la demora a las dificultades económicas municipales, por lo que se había hecho preciso la suscripción de conciertos entre la Corporación Provincial y los ayuntamientos deudores por el pago de los atrasos.

Este punto supuso un debate en el que los diputados Nájera de la Guerra y Polanco hicieron ver que los conciertos había que respetarlos en función de la seriedad de la Diputación, «que debe dar esa nota en todos sus actos», máxime cuando el cobro de aquellas resultas era irrealizable por las dificultades que se causarían a los ayuntamientos deudores, los cuales en función del concierto suscrito no tenían asignados en sus presupuestos la totalidad de dichos gastos, sino solamente lo previsto amortizar en el referido año. El Presidente (señor Néstar) le respondió que:

«Si bien reconoce que en un régimen normal estarían muy puestas en razón las manifestaciones de dicho señor (Nájera), en las circunstancias por que atraviesa no hay más que acatar y respetar lo que se ordena» (5).

Tras otras intervenciones se aprobó el presupuesto extraordinario con el voto de los diecisiete diputados presentes y se pasó a tratar diversos asuntos de trámite sin mayor importancia, ratificando los acuerdos de la Comisión Permanente provincial, etc. Pocos comentarios podemos hacer al respecto, pues si la Ley provincial de 1882 negaba autonomía a las diputaciones provinciales y las consideraba como corporaciones dependientes del Ministerio de la Gobernación, en tiempos de la dictadura de Primo de Rivera eran también objeto de arbitrariedades e intervencionismos.

La convulsión profunda en las diputaciones provinciales fue producida por el Real Decreto de 12 de enero de 1924, que ordenaba la disolución de todas las diputaciones provinciales de España, con excepción de las de Alava, Guipúzcoa, Navarra y

(4) Ibídem.

(5) Ibídem, folio 28, 4. 
Vizcaya. También determinaba que la designación de los diputados provinciales, y siempre a título interino, sería realizada por los gobernadores civiles (6).

\section{SITUACION DE LA DIPUTACION DE PALENCIA EN 1924}

El artículo $6 .^{\circ}$ del Real Decreto de 12 de enero de 1924 disponía que las corporaciones provinciales elevasen al Ministerio de la Gobernación en un plazo de quince días, prorrogado posteriormente a treinta, una memoria sucinta, detallando los defectos $y$ anomalías que observasen en su funcionamiento, proponiendo las medidas necesarias para corregirlas. Esta diposición permitió a la Dirección General de Administración conocer la situación real de las corporaciones, y al reunir todas las memorias en un tomo editado en 1925 ha permitido disponer de una valiosa información (7).

Sin estar normalizadas todas las memorias, se estructuraron según los capítulos de los presupuestos provinciales, incluyendo además un epígrafe final sobre la cuestión regional. El panorama era desolador: Deficiencias y carencias; índices de mortalidad en los centros benéficos, siempre muy superiores a los habituales en otros países. Carreteras y caminos provinciales prácticamente inexistentes o dificultosamente atendidos; el fomento de la economía provincial, sin abordar.

Se atribuía unánimente esta deplorable situación a la deficiencia de medios económicos de las diputaciones provinciales, pues su hacienda se basaba en los magros contingentes municipales, que unido a las cargas del Estado y ausencia de autonomía prevista en la Ley Provincial daban lugar a unas corporaciones que con dificultades atendía a sus obligaciones benéfico-asistenciales, renunciando en la práctica a hacer frente a la actividad de fomento, obras públicas, caminos, etc. Sintetizaba la situación la Diputación de Badajoz, al decir que, por las razones señaladas, se habian convertido sólo en: "Tribunal de incidencias municipales y administrador de establecimientos benéficos» (8).

(6) Véase Calvo Sotelo, J: Mis servicios al Estado. Segunda edición, Madrid, IEAL, 1974, p. 22. Para el autor, ula persistencia de las diputaciones se tenía en pie después de la remudación de los ayuntamientos por una inexplicable inercia del Directorio». VALLINA VELARDE, J. L.: «Pasado, presente y futuro de la región», en Cincuentenario del Estatuto Municipal, Madrid, IEAL, 1974, p. 673, interpreta que el Real Decreto era expresión del sentimiento regional que al principio inspiró a Primo de Rivera y Calvo Sotelo, con lo que se facilitaba un mejor y más amplio reconocimiento de la región.

(7) Anuario de la Vida Local, 1924. Administración Provincial, Mancomunidades, Diputaciones Provinciales y Cabildos Insulares. Madrid, Dirección General de Administración, 1925. tomo I.

(8) Véase Anuario, op. cit., p. IX.

REVISTA DE ESTUDIOS. -6 
La Diputación de Palencia era partícipe de esta situación, aunque no ocupaba un lugar destacable por su extrema gravedad. Curiosamente los redactores de la memoria -El Pleno de los Diputados- no mostraban acritud hacia sus antecesores, y por lo general evitaban descalificaciones, limitándose a exponer el problema y culpar a la carencia de medios económicos todas las deficiencias. Sin embargo, el tono mantenido habitualmente con las corporaciones precedentes se romperá al referirse al gobierno central y al sistema político del pasado, materializando en la Ley de Autorizaciones del señor Alba, promulgada en 1917, la causa de múltiples males económicos.

\section{A) Servicios de Beneficencia y Asistencia Social}

Entre los problemas que aquejaban a estos servicios y detallaba la memoria, encontramos el de su falta de capacidad, pues construidos para 200 asilados, albergaba más de 500 (9). Un antiguo claustro era la Maternidad, donde carecían de calefacción y la higiene era casi inexistente, "las asiladas dan a luz sobre las mismas camas en que han de dormir, y en esos mismos lechos se hacen las operaciones». La Casa Cuna tenía el mismo problema: No había patio, ni jardín, ni lugar de recreo; dormían las amas junto a los niños, con una estufa por todo medio de calefacción y carecían de incubadora. En la enfermería, con capacidad para seis cunas, había 12, sin clasificación de enfermedades, con el riesgo natural de contagios infecciosos. Los asilados se encontraban en análogas circunstancias, sin lugares de estancia adecuados, carentes de higiene y hacinados. La alimentación era insuficiente, sólo se comía carne, en escasa cantidad, los domingos; el resto de la semana, garbanzos y alubias constituían la dieta habitual. Todas estas circunstancias se reflejan en una mortalidad del 24,75 por 100 en toda la población asilada, y con relación a los niños durante los dos primeros años de edad, el 62 por 100 (10).

Respecto al manicomio, encomendado a comunidades religiosas, elogiadas por los miembros del Pleno, los locales no se encontraban a la «altura que reclama la instalación de un verdadero frenocomio", contrastando con los modernos locales propiedad de dichas comunidades (San Juan de Dios) y dedicados a la atención privada. Pero como hemos indicado anteriormente, éste era un panorama común a casi todas las diputaciones, si bien la de Palencia no era de las más graves.

(9) Véase Anuario, op. cit., p. 269.

(10) Véase Anuario, op. cit., p. 271. 


\section{B) Carreteras}

La información sobre carreteras provinciales abarca desde 1915 a 1924, y las inversiones se refieren a gastos de mantenimiento y conservación, con una media anual de 49.180 pesetas. En la cantidad para 1924 (54.565 pesetas) se imputaban los gastos de personal, acopio de piedra machacada para la conservación (946 metros cúbicos en 1922), etc. (11).

El parque de maquinaria era muy elemental, pues no tenía ni un simple rodillo. A pesar de todo, el juicio que merece al Pleno de la Diputación la conservación de la red provincial de carreteras es bueno, exceptuando el tramo de siete kilómetros de carretera de Calabazanas a Esguevillas, muy deteriorada (12).

La memoria se refiere al arbolado en las carreteras, prácticamente inexistente, excepto algunos grupos de chopos en la de Villasarracino a Buenavista $y$ un vivero en Alba de Cerrato, y proponía plantar en diez años dos filas de árboles distanciados cinco metros cada uno para toda la red provincial, que supondría 36.000 árboles en dicho plazo, que defenderían el firme de la sequedad y el calor, evitarían la erosión y constituirían una barrera para la invasión del camino para los propietarios colindantes. Además, existiría un valor marginal al talarse cada treinta años. El planteamiento era realmente sencillo, pero se inspiraba en un concepto de protección a la naturaleza y al medio ambiente, infrecuente para la época (13).

El anuncio hecho a fines de 1924 por Calvo Sotelo sobre la probable transferencia a las diputaciones de la conservación de carreteras, de acuerdo con las posibilidades del futuro Estatuto Provincial, motivó la alarma del Diario Palentino, que el 27 de diciembre publicó un artículo sobre el asunto, al que calificó de trascendental, al tiempo que albergaba serias dudas sobre la capacidad de las diputaciones para asumir aquellas competencias.

Salió al paso la Comisón Permanente en la sesión del día 30 de diciembre, disipando los temores del periódico, pues si la conservación de las vías se encomendaba a la corporación, el Estado traspasaría los medios precisos, consiguiendo la igualdad entre todas las provincias eliminando privilegios, en alusión a las que disfrutaban del régimen de conciertos económicos. Concluía la Permanente tranquilizando a la opinión pública, pues en caso de llevarse a cabo la reforma, no supondría nuevo gravamen sobre los

(11) Véase Anuario, op. cit., p. 274. Al parecer la existencia de una cantera para la extracción de piedra machacada colaboraba al deterioro de la carretera.

(12) Véase Anuario, op. cit., p. 277.

(13) Véase Anuario, op. cit., p. 276. 
pueblos, pues la diputación siempre «ha demostrado con hechos que sabe cumplir sus compromisos», aun dentro de lo exiguo de las cantidades presupuestadas (14).

\section{C) Comunicaciones}

La ampliación de la red ferroviaria fue otro de los puntos que se abordó durante el período dictatorial. A este respecto existían de antes dos proyectos correspondientes a dos nuevas líneas: Palencia-Guardo y Palencia-Aranda de Duero.

El primero, incluso había salido a subasta su construcción varias veces, y fue declarada desierta. Promesa obligada en campañas electorales, buscaba comunicar las comarcas mineras del norte de Palencia y las vegas de Carrión y Saldaña con la capital, lo que reportaría indudables beneficios, por tratarse de una rápida vía de transporte que contaba con el apoyo de la diputación (15).

El proyecto del ferrocarril Palencia-Aranda también tomó cuerpo nuevamente en 1924, al proponer las diputaciones de Burgos y Palencia crear una mancomunidad interprovincial que permitiera su construcción. La propuesta era ventajosa al conectar con la línea de Ariza que concluía en Barcelona y ahorrar una considerable distancia en los recorridos entre Galicia-Asturias y Cataluña-Levante. El asunto fue abordado por la Comisión Permanente el día 24 de abril de 1924, y según la citada memoria, uno de los objetivos a cumplir, transformando en realidad un viejo sueño. Pero imposible sin un cambio radical en la situación de las diputaciones que diese paso a un nuevo régimen provincial, liberado de cargas privativas del Estado, dotado de recursos propios y con amplia autonomía e independencia para afrontar estas empresas (16).

El apoyo popular al ferrocarril Palencia-Aranda tuvo una nueva manifestación en marzo de 1925, cuando los alcaldes del partido de Baltanás, presidentes de sindicatos y asociaciones obreras, se dirigieron al subsecretario de Fomento reiterando la inclusión en el plan general de preferente construcción la línea Palencia-Aranda por sus ventajas para la comarca y la provincia en general (17).

Completaba el plan provincial de comunicaciones extender la red telefónica a toda la provincia, proyecto en el que la diputación manifestaba su incapacidad económica para patrocinar la obra, ya que su presupuesto de ingresos se agotaba en las

(14) Véase ADPLA, Comisión Provincial, sesión del día 30 de diciembre de 1924, folios 101 vuelto y 102.2 .

(15) Véase Anuario, op. cit., p. 282.

(16) Ibidem, op. cit., p. 282:

(17) Véase ADPLA, Comisión Provincial, sesión del día 10 de marzo de 1925, folio 15. 
«debidas atenciones a la beneficencia y con la abrumadora e injusta carga que sobre ella echara el decreto del señor Alba, relativo al pago de atenciones exclusivamente del Estado» (18).

\section{D) Otros aspectos de la gestión provincial en 1924}

La dictadura de Primo de Rivera en el ámbito local se caracterizó por la dinámica que imprimía a todas las actuaciones, plazos cortos, decisiones inapelables, etc., la nueva diputación palentina, designada por el gobernador civil, se constituyó el 20 de enero, y al día siguiente la Comisión Provincial, presidida por la primera autoridad civil, tras lo cual comenzó el trabajo de los diputados, consistente, según el gobernador, en evacuar "los informes que se interesen en cuantos asuntos tenga que resolver el gobierno de provincia» (19), panorama no muy halagüeño en cuanto a la actividad de la corporación, que una vez más iba a quedar relegada a un papel de escasa trascendencia autonómica, mediatizada por conceptos centralistas.

¿Cuál fue la reacción de la Diputación palentina ante la reforma municipal que se produjo? En la sesión del 10 de marzo, dos días después de aprobarse el Estatuto Municipal, propuso la Comisión Permanente celebrar un cursillo urgente de conferencias doctrinales y técnicas, dirigidas a los secretarios $y$ alcaldes sobre el nuevo régimen local, colaborando en divulgar el Estauto. $Y$ pese a la restricción que suponía dicha norma a todas las competencias consultivas y resolutivas que sobre los ayuntamientos tenía la Comisión Permanente, ésta se ofreció para evacuar las consultas de los ayuntamientos y alcaldes sobre el nuevo sistema. Aparte de felicitar al señor Calvo Sotelo upor la labor tan meritoria que había llevado a cabo» ... "y pone de relieve una vez más las excepcionales condiciones de ilustración y competencia que le distinguen y que honran a esta provincia en la cual tiene las más caras afecciones» (20).

El régimen jurídico de las entidades municipales había quedado atribuido en el Estatuto a los Tribunales de Justicia en las diversas vías (artículos 252 a 276), pero la revisión de los libros de actas de la Comisión Permanente palentina, y así parece ser que sucedía en el resto de las diputaciones, mantienen sus funciones informativas al gobernador en los asuntos municipales, lo que realmente parece una contradicción con el texto del Estatuto y con lo manifestado en

(18) Véase Anuario, op. cit., p. 282.

(19) Véase ADPLA, Comisión Provincial, sesión del día 21 de enero de 1924.

(20) Ibídem. Sesión del 12 de marzo de 1924, folio 20. 
la sesión del 12 de marzo, pero sin duda la realidad era así. Entre varios informes y asuntos de menor cuantía a lo largo del año, hemos seleccionado el que se tramita con motivo del expediente instruido por el teniente coronel de la Guardia Civil don Angel Ramos, delegado del gobierno de provincia, por las irregularidades en diversas obras municipales del ayuntamiento de la capital, realizadas a partir del 6 de febrero de 1922. Tras un prolijo y complicado expediente, se llega a la evidencia de que sólo estaban sin justificar 306,50 pesetas, y al no existir otras pruebas que inculpasen a ningún funcionario ni político local, acordaron proponer al gobierno de provincia se ordenase al ayuntamiento que si de sus cuentas resultase la cantidad citada como indebidamente pagada le fuese reclamada al contratista (21). Poca entidad tenía la cuestión y el afán presuntamente moralizador y ejemplarizante del directorio frente a la corrupción municipal, quedaba en Palencia como un esfuerzo baldío e innecesario.

Otros muchos asuntos pasaron por la Comisión Permanente en cada sesión, la mayoría de trámite, que no implicaban un aumento de la gestión y la actividad respecto a otras épocas. Concluyó el año 24 con la llegada de un nuevo gobernador, procedente de la alcaldía de Oviedo, que saludará a la comisión el 6 de diciembre, dedicando elogios a la provincia como modelo de honorabilidad y administración (22).

\section{GESTION Y ACTIVIDAD DE LA DIPUTACION DE PALENCIA DESDE 1925 A 1930}

El Estatuto Provincial de 20 de marzo de 1925 incorporó las provincias a la obra legal del señor Calvo Sotelo, y marcó, sin duda, un hito fundamental en la administración de las provincias, pues rompió, al menos sobre el papel, con la dependencia gubernamental que figuraba en diversas leyes del siglo XIX, incluida la de 1882. Como el profesor GARCÍA DE ENTERRíA afirma: «La aportación más indiscutible del Estatuto Provincial al Derecho fue sin duda la verdadera aparición de la provincia como entidad local» (23), pues, como es sabido, tal figura territorial había sido un organismo de la Administración periférica del Estado, a las órdenes del gobernador civil, fiel correa transmisora del caciquismo y con la misión primordial de coordinar y supervisar a los Ayuntamientos.

(21) Ibídem. Sesión del 11 de noviembre de 1924, folio 86.2.3.4.

(22) Ibídem. Sesión del 6 de diciembre de 1924, folio 93, 4.

(23) Véase GARCIA DE ENTERRIA, Eduardo: "La Provincia en el Régimen local español» en Problemas actuales de Régimen Local, segunda edición, Sevilla, Universidad, 1986, p. 36. Concepto que ha sido reiterado por la mayoría de los autores. 
El Estatuto rompe estas viejas funciones, e invierte la situación: los Ayuntamientos agrupados constituyen la provincia, y en virtud del sistema de Carta intermunicipal podían asociarse rebasando los límites del territorio provincial. Tuvo igualmente gran importancia el nuevo enfoque que dio el Estatuto a diversos aspectos del régimen jurídico provincial. Puede considerarse como un verdadero programa de gobierno provincial el que ofreció el contenido competencial del artículo 107 del Estatuto a favor de las Diputaciones.

"Construcción y conservación de caminos; construcción y explotación de ferrocarriles y tranvías interurbanos; establecimientos de líneas de comunicación telefónica; desecación de terreno, encauzamiento y rectificación de ríos; establecimiento y sostenimiento de instituciones de beneficencia, higiene y sanidad; concursos y exposiciones para fomentar los intereses morales y materiales de la provincia; instituciones de crédito popular, agrícola y municipal, de ahorro, de cooperación, de seguros sociales y de casas baratas; establecimiento de escuelas de agricultura, granjas y campos de experimentación, cátedras ambulantes para difundir la enseñanza agrícola; escuelas industriales, de bellas artes, de sordomudos, de ciegos, etc., fomento de la ganadería y de la riqueza forestal; conservación de monumentos; recaduación de las contribuciones del Estado» (24).

Sin embargo, la experiencia demostró muy pronto que los medios eran insuficientes para renovar la vida local española (25). Aunque siempre hemos pensado que tampoco existía firme voluntad política de impulsar dicha reforma, que, por otro lado, fue avanzadilla de otras iniciada posteriormente, sin ir más lejos, la cooperación de las Diputaciones con los Ayuntamientos, eje básico de la actual reforma local española de nuestros días, apareció como idea general por primera vez en el Estatuto Provincial. Pese a que

(24) Múltiples han sido los autores que han estudiado el tema, una pequeña muestra en: MARTín Retortillo. S. ARgullol: E. Descentralización..., op. cit., pp. 315-340. PAREJo ALFONSO, L.: La Región..., op. cit., pp. 143-158. Ultimamente en: Derecho básico de la Administración Local. Barcelona, Ariel, 1988, pp. 77-81. MORELL OCAÑA, L.: La Provincia, Madrid, Tecnos, 1987. Idem: El régimen local español, Madrid, Cívitas, 1988. Vol. I, pp. 690-692. DíEz GONZÁlez, F.: "La provincia, eje de una política para la vida local», en Memoria de la Gestión Corporativa de la Excma. Diputación Provincial de León, 1953, León, 1954, 25 pp. Idem: "El esquema provincial y sus incidencias. En torno al Estatuto Provincial», en Cátedra Calvo Sotelo. Conferencias 1974. Madrid, IEAL, 1975, pp. 83-131. GonZÁLEZ CASANOVAS, J. L.: Las Diputaciones provinciales en España. Historia de las Diputaciones, 1812-1985, Madrid, Mancomunidad General de Diputaciones de Régimen Común, 1986, pp. 121-138. VALLINA, V.: La Provincia local de España, Oviedo, 1963. VAllinA, J. L.: Pasado..., op. cit.

(25) Véase Diez GonzÁlez. F.: La provincia..., op. cit., p. 15. 
no fue plasmada de forma articulada, si estaba presente en diversos puntos del texto, por ejemplo, cuando consideraba la obligación de incluir en sus presupuestos cantidades dedicadas a subvencionar obras sanitarias, como abastecimientos de aguas, eliminación de basuras y saneamientos de zonas palúdicas (26).

En consecuencia, destacaremos algunos detalles de la gestión provincial, sobre todo los novedosos en la Diputación palentina desde 1925, con la entrada en vigor del Estatuto Provincial, hasta 1930. Asignaba el artículo 57 del Estatuto Provincial a la provincia de Palencia seis diputados provinciales directos, elegidos según el minucioso procedimiento previsto en el título III, capítulo I, que nunca llegó a convertirse en realidad, pues la disposición final del mismo texto ordenaba la constitución de las Diputaciones Provinciales el 1 de abril, «con las personas que los gobernadores civiles designen", y aunque el libro primero del Estatuto entró en vigor, las elecciones se posponían a la realización de un nuevo censo electoral. La contradicción era flagrante, pues si a los gobernadores se les restringían algunas atribuciones en el texto estatutario, en las disposiciones finales se les encomendaba el nombramiento de los diputados en la culminación de un intento de perpetuar la situación que había denostado don Miguel Primo y que resultó una de las causas alegadas -la erradicación del caciquismo-, en septiembre del 23.

El profesor PALOMARES ya ha indicado la composición de la nueva Diputación y de su Comisión Provincial Permanente. Esta se constituyó el día 3 de abril de 1925, y acordó reunirse en sesión ordinaria dos veces al mes, el 13 y 23 de abril, sin perjuicio de los extraordinarios. La actividad de la Comisión se reguló por el Reglamento de funcionamiento, aprobado el día 3 de junio de 1925 (27), conforme señala el artículo 117.1 del Estatuto Provincial.

La gestión de una Diputación se evalúa por diversos parámetros, e indudablemente uno de ellos es el número de asuntos que se tratan en las sesiones de la Comisión o del Pleno. El examen de los libros de actas de la Comisión Provincial de la Diputación de Palencia en el período señalado ofrece una idea del aumento de actividad de dicha Comisión, incluidos los asuntos que pudiéramos considerar de trámite, entre los que figuran dos aspectos de la gestión

(26) DíEZ GonzÁlez, F.: El esquema provincial..., op. cit., p. 96. En este sentido la diputación de Palencia incorporó a su presupuesto de 1926 (capítulo 7, artículo 3), 50.000 pesetas para subvencionar las obras de carácter sanitario de los ayuntamientos. Quedó regulado el procedimiento de cooperación embrionaria por las bases que propuso el diputado señor MARTIN ESCOBAR, y que fueron aprobadas por unanimidad en la sesión de la Comisión Provincial del día 19 de abril de 1926. D. 8 folios 43 y 44 .

(27) Véase ADPLA, Comisión Provincial, sesión del día 3 de junio de 1925, folio 15.3. 
provincial que experimentan un notorio crecimiento: la beneficencia y las obras públicas. A ello contribuyó eficazmente la nueva situación económica de las Diputaciones, que a partir del año 1926 conocería una cierta euforia dado el incremento de las cifras presupuestarias, pues, como veremos después, éstas se duplicaron y a finales de la década triplicaron respecto al año 1923.

Como muestra de la actividad corporativa palentina, seleccionamos varios asuntos, no de trámite, que fueron objeto de discusión y decisión por la Comisión Provincial, aparte de los de carácter económico que estudiamos en capítulo posterior y advirtiendo que la mayoría de ellos fueron abordados en varias ocasiones y años:

Sanidad, Campaña antirrábica, Dispensarios, Inspección sanitaria, Clínica Oftalmológica, Calamidades e Inundaciones.

Fomento, Huerta de la Diputación, Maquinaria, Sericultura, Congreso ceralista, Abastecimientos de aguas, Laguna de la nave, Ferias y Exposición Iberoamericana.

Becas, Comisión de monumentos, Exposiciones y Turismo Becados de París, Cuadros de pintores provinciales, Pensiones para artistas, Monumentos históricos, Cátedras ambulantes, Catálogo monumental, Construcciones escolares, Exploradores, Banda de música, Biblioteca Provincial, Imprenta, Casa de Palencia en Madrid, Agrupación Castellana de México y Casa de Palencia en Bilbao.

Veamos algunos de estos aspectos gestinados por la Diputación.

\section{A) Instituto de Higiene}

La Comisión Provincial cumplimentó el artículo 128, c), del Estatuto Provincial, en la sesión del día 3 de julio de 1925, complementándolo en la de 8 de agosto, con unas instrucciones que determinaban su plantilla y normas generales de actuación. Formaban la plantilla del Laboratorio palentino un jefe, dos ayudantes, un mozo, tres conductores y un ordenanza. Las tres primeras plazas deberían cubrirse por oposición y las restantes por prueba de aptitud ante un Tribunal (28).

Los cometidos de aquellos centros versaban sobre la preparación, conservación y distribución de vacunas, diagnóstico de

(28) Véase ibídem, sesión del día 8 de septiembre de 1925, folio 36 vuelto. Estas instrucciones tendrían que adaptarse al Reglamento de Sanidad Provincial, aprobado por Real Decreto de la presidencia del Directorio Militar de 20 de octubre de 1925. 
enfermedades infecciosas y cancerígenas, traslado urgente de enfermos infecciosos, desinfección y desinsectación, investigación del paludismo e impartición de cursos de extensión sanitaria y de higiene. Todo ello según la sanidad e higiene pública de la época, surgidos a partir de la primera guerra mundial y que servirían para sentar las baes de la moderna sanidad.

En las instrucciones se hacía constar que para disfrutar de los beneficios de pobre, los internados debían justificar su condición, conforme a las bases aprobadas por la Diputación para reconocer la pobreza en las solicitudes de ingreso en los establecimientos provinciales, circunstancia que antes no era preceptiva y producía un gran desequilibrio en la economía de los servicios de Beneficencia; el certificado médico completaba el trámite. Los enfermos no pobres debían abonar los gastos ocasionados, y los de ambulancia en caso de utilizarla.

Igualmente recordaban a los médicos la obligación de remitir mensualmente a la Inspección Provincial de Sanidad la estadística de los enfermos asistidos, principalmente en los casos infecciosos. La recomendación era más apremiante en los casos de paludismo, que los médicos y veterinarios pondrían en conocimiento del presidente de la Diputación con toda urgencia, para tomar las medidas oportunas de control y erradicación de la enfermedad. Respecto al inspector provincial de Sanidad, sus funciones se limitaban a la alta inspección, sin perjuicio de cooperar en casos de epidemias y otras situaciones graves e imprevistas. Concluían las instrucciones con el inventario de muebles y equipo entregados al jefe del laboratorio, así como los procedentes de la extinguida Brigada Sanitaria, la previsión de dietas por desplazamientos y la obligatoriedad de llevar un libro-registro de casos (29).

\section{B) Desarrollo agrario y repoblación forestal}

El antiguo propósito regeneracionista de la repoblación forestal y de la recuperación agraria tuvo en las instituciones locales españolas de la época un protagonismo considerable, y rara fue la Corporación que no instituyó su fiesta del árbol, hizo campañas repobladoras, etc. A esto se unió en la región de Castilla y León, eminentemente agrícola, el estudio y fomento de los cultivos con criterios más modernos y nuevas técnicas. Para ello la Diputación de Palencia encargó al diputado señor Rojo Flores elaborar unas «bases para la implantación de viveros forestales y campos agrícolas agropecuarios» en cada partido judicial presentadas a la

(29) Véase ibidem, sesión del día 8 de agosto de 1925, folios 37 y 37 vuelto. 
Comisión Provincial y aprobadas en la sesión del día 14 de octubre de 1925 (30).

En las bases se exponían los objetivos de los campos agrícolas concebidos como centros de demostración para «difundir entre los labradores los resultados adquiridos en los centros experimentales», no sólo referidos a labores agrícolas, sino al uso de abonos y semillas. El fomento ganadeero preveía la creación de espacios (praderas artificiales) para desarrollar en lugares sin hábito pecuario la cría de diversas especies animales. En las comarcas de tradición ganadera los campos debían ser agropecuarios y subvencionar la adquisición de sementales seleccionados para mejorar y fomentar la cabaña provincial. Finalmente los viveros forestales facilitaban plantones de las especies idóneas a los municipios para repoblar los espacios comunes.

Para instalar un campo los municipios cederían gratuitamente a la Diputación el terreno necesario. La Corporación provincial, además del personal facultativo, aportaría una subvención inicial de 1.000 pestas para su establecimiento y 1.500 ó $1: 200$ anuales para el sostenimiento del campo agropecuario o del vivero, respectivamente. El órgano de gobierno lo constituía un Patronato formado por el alcalde, el párroco, los presidentes de los sindicatos agrícolas locales, el diputado o concejal corporativo y un maestro nacional. El Patronato debía levantar actas de sus reuniones y remitirlas a la Diputación, elaborar un reglamento de funcionamiento y distribuir los plantones o productos, atendiendo a las demandas de la comunidad. La Diputación se reservaba el derecho de retirar las subvenciones en caso de incumplirse las funciones de los centros. Finalmente, contra la gestión del Patronato podrían recurrir los pueblos y los articulares ante la Diputación cuando considerasen preteridos o perjudicados sus derechos (31).

\section{C) El ferrocarril de Palencia a Guardo}

Ya vimos los intentos de la Diputación de Palencia para realizar el ferrocarril de Guardo, reflejados en la Memoria de 1923 (32). La Diputación insistió y en abril de 1927 el Gobierno aprobó un Real Decreto para subvencionar su construcción, con lo que se resolvían las dificultades más apremiantes. A tal fin, se creó en enero de 1929 una Mancomunidad para gestionar su construcción, formada por la Diputación Provincial de Palencia, los Ayuntamientos de la

(30) Véase ibídem, sesión del día 14 de octubre de 1925 , folios 60 vuelto a 60.4 .

(31) Véase ibídem, sesión del día 14 de octubre de 1925 , folio 60.4 .

(32) Véase anuario..., op. cit., p. 282. 
capital, Carrión, Saldaña, Guardo y Villoldo, y las sociedades. mineras "Antracitas de Villoldo» y «San Luis», que aportaban 500.000 pesetas.

El protagonismo de la Diputación palentina era decisivo, según se reflejaron las bases que regulaban su constitución, aprobadas el 14 de enero de 1929 (33). La Junta directiva de la Mancomunidad radicaba en la Diputación y estaba compuesta por el presidente, vicepresidente, el diputado ponente de obras provinciales, los alcaldes de los pueblos mancomunados y los representantes de las sociedades mineras.

Estaba facultada para gestionar del Gobierno la concesión del ferrocarril y acordar su construcción por administración o subasta, explotarlo directamente o encargárselo a un tercero, así como desempeñar las especificaciones de carácter económico propias de las Mancomunidades. Por último, la Diputación se comprometía, en la base octava, a financiar los proyectos y estudios para construir el ferrocarril. Aprobadas las bases se acordó remitir un ejemplar de las mismas a los Ayuntamientos y entidades para que prestasen, si procedía, su aprobación y constituir la Mancomunidad seguidamente (34).

\section{D) Caminos vecinales}

El artículo 133 del EP determinaba que las Diputaciones dotasen de caminos vecinales su territorio para que ningún núcleo de población superior a 75 habitantes quedase incomunidado. Al encomendar la construcción y conservación de caminos a las Diputaciones, el Estado preveía subvencionar el servicio durante diez años; la atribución de competencias se cerraba con la obligatoriedad de redactar un uplan provincial de caminos vecinales» en el plazo de un año. Asunto de esta transcendencia se complementaba con el desarrollo reglamentario de obras y vías provinciales, aprobado por Real Decreto de 15 de julio de 1925, donde, se recogía con detalle la elaboración del Plan, traspasos de caminos vecinales y puentes económicos del Estado a las Diputaciones, la coordinación interprovincial, expropiaciones, etc.

El incremento de la actividad provincial en materia de caminos vecinales fue indudable a partir de 1926, como se puede comprobar revisando la documentación de la Comisión y Pleno de la Diputación palentina. Vimos anteriormente la situación de los caminos vecinales en la Memoria de 1923 y las dificultades para

(33) Véase ADPLA, sesión del día 14 de enero de 1929, folios 4-4, 5 y 5 vuelto.

(34) Véase ibídem. 
hacer frente a las necesidades planteadas. Las nuevas disposiciones estatutarias tratarán de remediar la situación, y lo harán en cierta medida, quizá menor de lo que la propaganda oficial de la época quiso demostrar.

Una muestra de tal actividad la encontramos en febrero de 1927. Aún continuaba la reparación de la carretera de Calabazanos a Esguevillas (kilómetros 1-3 y 4-7) y simultáneamente se trabajaba en la construcción de los caminos vecinales de:

Matamorisca a la carretera de Guardo a Burgos.

Villarobejo a la carretera de Sahagún por Saldaña.

Itero Seco a la carretera de San Mamés a Bahíllo.

Pesquera de los Infantes de Aguilar a Villadiego.

Dehesa de Romanones a la de Puebla a Alar del Rey.

El 26 de febrero se adjudicaron nuevas construcciones de caminos vecinales desde:

Villacidaler a la carretera de Rioseco-Villasarracino.

Villota del Duque a la carretera de Saldaña-Masa.

Las cuantías eran de 7.775 para el primer tramo y de 27.540 el segundo (35).

La Diputación palentina cumplió el mandato estaturario, redactando un plan que, pese a ser aprobado, adolecía de algunas deficiencias que motivaron la presentación de una moción por el diputado Rojo Flores, haciendo constar que varios pueblos quedaban incomunicados al no haber sido incluidos en el Plan, por lo que éste debía ampliarse e incorporar en estudio complementario a todos los pueblos que careciesen de caminos (36).

No obstante, el Plan aprobado por la Diputación en junio de 1927 contenía múltiples especificaciones técnicas y económicas para ejecutarlo en un plazo de cinco años. Un mes después se puso a disposición de los diputados todos los informes evacuados por el ingeniero jefe de Vías y Obras e interventor de Fondos, al objeto de resolver deficiencias como la señalada anteriormente y modificaciones del Plan que al parecer resultaron frecuentes, entre la que destacaremos la solicitada por el Ayuntamiento de Barruelo de Santullán, que, invocando altos intereses económicos, proponía comunicar las provincias de Santander y Palencia, a través del itinerario Barruelo, Vallejo, Valberzaro, Mata de Hoz y Olea, frente a un primitivo proyecto de camino vecinal de Barruelo a enlazar con

(35) Véase ibídem, sesión del día 14 de marzo de 1927, folios 17 y ss.

(36) Véase ibídem, sesión del dia 14 de julio de 1927. 
la carretera de Matamorosa a Cantoral, en el límite de la provincia por Orbó. Aportaba los acuerdos de todas las Corporaciones afectadas y la solicitud a la Dirección General de Obras Públicas para que autorizase la modificación por tratarse de un camino interprovincial (37).

A tal situación se daba prioridad en el Plan de Caminos -de acuerdo con lo dispuesto en la Orden de la Dirección General de Obras Públicas de 29 de abril de 1927, referente a la construcción de caminos interprovinciales- previendo la formalización de acuerdos de la Diputación de Palencia con las limítrofes para fijar el punto de paso de la divisoria y realizar las obras simultáneamente. A este propósito la Corporación acordó elaborar una relación con el orden de prelación de los caminos previstos y publicarla en el BOP para conocimiento de los pueblos afectados (38).

\section{LA HACIENDA PROVINCIAL DE PALENCIA}

La gestión del período no puede desvincularse de la Hacienda expresada en los Presupuestos del decenio en dos fases: desde 1920 hasta la entrada en vigor del Estatuto Provincial y desde 1925 hasta 1930. Se justifica plenamente esta cesura, pues en materia presupuestaria, existe una continuada hasta 1924, incluso después del golpe militar y disolverse la Diputación, pese a que en ese año casi se duplique el Presupuesto. Mientras que al entrar en vigor el Estatuto Provincial, advertimos un cambio radical en la elaboración del Presupuesto y una nueva concepción de partidas y capítulos. EI incremento presupuestario debió corresponderse con un aumento de la actividad de la Diputación provincial, como se detecta al analizar el libro de actas de la Comisión Permanente palentina.

\section{A) La Hacienda provincial (1920-1924)}

La Diputación tenía, entre 1920 y 1924, un Presupuesto de Gastos e Ingresos que oscilaba entre las $860.366,35$ pesetas para el bienio 1920-1921 y las 902.149,68 de 1921-1922, lo que supuso durante el cuatrienio una media anual de 880.595,5 pesetas. Cantidad a todas luces insuficiente para hacer frente a las obligaciones provinciales (39).

(37) Véase ibídem, sesión del día 26 de julio de 1927, folios 57 y 58.

(38) Véase ibídem, sesión del día 12 de mayo de 1927.

(39) Véase Anuario, op cit., p. 276. 


\section{PRESUPUESTOS DE INGRESOS Y GASTOS AÑos 1920-1924}

\begin{tabular}{lr|r}
\hline & & \multicolumn{1}{c}{ Pesetas } \\
\cline { 2 - 3 } Ejercicio $1920-1921 \ldots \ldots \ldots$ & $860.365,35$ \\
Ejercicio $1921-1922 \ldots \ldots \ldots$ & $902.149,68$ \\
Ejercicio $1922-1923 \ldots \ldots \ldots$ & $880.579,49$ \\
Ejercicio $1923-1924 \ldots \ldots \ldots$ & $879.286,33$ \\
Ejercicio $1924-1925 \ldots \ldots \ldots$ & $1.369 .901,24$ \\
\hline
\end{tabular}

Los ingresos eran básicamente el capítulo IV: Repartimientos entre los pueblos, que supuso el 83,63 por 100 de media para los cuatro años sobre el total de los ingresos. El resto de los capítulos fueron:

\begin{tabular}{l|l}
\hline & \multicolumn{1}{|c}{ Porcentaje } \\
\cline { 2 - 2 } Rentas $\ldots \ldots \ldots \ldots \ldots \ldots$ & 0,41 \\
Instrucción pública $\ldots \ldots$ & 7,73 \\
Beneficencia $\ldots \ldots \ldots \ldots$ & 1,73 \\
Ingresos extras $\ldots \ldots \ldots$ & 0,70 \\
Resultas $\ldots \ldots \ldots \ldots \ldots$ & 5,72 \\
Reintegros $\ldots \ldots \ldots \ldots$ & $0,80 \quad(40)$ \\
\hline
\end{tabular}

Con tales antecedentes se elaboró el presupuesto de 1924, aprobado en sesión de 12 de enero de 1924. Supuso un incremento notable sobre los anteriores, pues alcanzó 1.369.901 pesetas, casi medio millón más que el ejercicio precedente. Los aumentos en los ingresos habrá que buscarlos en los capítulos IV (Repartimientos entre los pueblos), con 915.791 pesetas, frente a 741.588 de 1923, y el XI (Resultas), con 345.880,84 (48.334 en 1923) (41).

Las razones de la triste situación de la Hacienda provincial palentina quedan reflejadas en la Memora de la Diputación, que las atribuye a tres causas: Internas, externas e impuestas. Entre las primeras figuran la construcción y el amueblamiento del palacio provincial, pagado ya en 1924, pero cuyas consecuencias aún se arrastran. La facilidad en el otorgamiento de pensiones y subvenciones. La mala política de personal y el deficiente régimen de ingresos en los establecimientos de la Beneficencia. Las externas se deben a la subida de todos los servicios y en el coste de los artículos provocadas por la guerra. Finalmente, la tercera causa,

(40) Datos procedentes de los Presupuestos publicados en los Boletines Oficiales de la Provincia, aprobados por la Diputación en 20 de febrero de 1920, 15 de febrero de 1921, 4 de marzo de 1922 y 10 de febrero de 1923. Elaboración propia.

(41) Ibídem. 
serán los servicios extraprovinciales impuestos como cargas a la Diputación por el Estado (42).

Esta es la causa, que creó más distorsiones, no sólo a la Diputación palentina como vimos anteriormente, sino a muchas de las de régimen común. La cuestión tenía su origen en la Ley de Autorizaciones de 1917, por la que el Estado impuso a la provincia el sostenimiento del personal y material de los centros de segunda enseñanza, normal e inspección, en los cuales la Diputación no tenía intervención administrativa alguna, y que pesaba sobre la Hacienda de manera onerosa al no compensarse con ningún ingreso adicional; pero, además, la discriminación se agudizaba al compararse con las grandes capitales, favorecidas al tener centros con matrícula muy superior a las de las pequeñas capitales, y que enjugaban una substanciosa partida de la aportación provincial. En el caso de Palencia el perjuicio era notorio, razón por la que el agravio resultaba mayor.

Las Corporaciones provinciales enviaron un mensaje al poder central en la Asamblea de Diputaciones del año 1921 para que les relevase de las cargas, sin que hasta 1924 se obtuviese respuesta, y aquí encontramos una crítica directa al gobierno constitucional y otra velada al directorio, cuando en la Memoria afirmaban:

«Han pasado casi cuatro años, y el poder central aún no ha resuelto la solicitud; pero en cambio ha ordenado el apremio para el cobro de tales cantidades contra las Corporaciones. El antiguo régimen calló ante la demanda: el nuevo pide el tributo» (43).

Las alusiones son claras respecto de la Diputación de Palencia en el mes de noviembre de 1923, cuando elaboró urgentemente un Presupuesto extraordinario para hacer frente a las demandas de la Hacienda por los descubiertos procedentes de ese concepto presupuestario. Como vimos hubo críticas y tibia oposición, que sería compartida y reiterada meses después por otros individuos que formaban parte de una Corporación designada por la autoridad gubernativa.

El criterio seguido por la Diputación para formar el capítulo de ingresos del Presupuesto extraordinario de 1923, fue tranferir del Ordinario las economías realizadas y los débitos contraídos por diversos Ayuntamientos en virtud del Convenio de mora a que hacíamos referencia con anterioridad, sin vigencia en aquel momento debido al apremio de la Hacienda estatal. El último dato

(42) Ibidem.

(43) Véase Anuario, op cit., p. 280 
es de interés, pues la Corporación optó por tal procedimiento, en lugar de realizar un nuevo repartimiento general entre todos los pueblos de la provincia, que les hubiese obligado a formular un nuevo Presupuesto agravando sus precarias economías. Con la fórmula aceptada no quedaba más remedio que romper los convenios de mora, pero en la práctica la percepción de las cantidades adeudadas resultarían muy difíciles de cobrar a la Diputación, la cual salvaba su responsabilidad elaborando el Presupuesto extraordinario y la trasladaba a los Ayuntamientos deudores sobre los que el Estado podría declarar el régimen de tutela.

Como indicábamos antes, el capítulo de Resultas del Presupuesto extraordinario ascendía a $274.405,50$ pesetas, y de esta cantidad correspondía al Ayuntamiento de la capital 199.711,25 pesetas, que había convenido con la Diputación aplazar veinte anualidades sin intereses. Tal actitud benevolente permitió al Ayuntamiento capitalino realizar importantes mejoras urbanas (44). Al formar la Diputación el Presupuesto extraordinario e incluir forzosamente en el mismo aquella cantidad, el Ayuntamiento palentino presentó dentro del plazo legal una reclamación contra el Presupuesto, que estudió y desestimó la Comisión Permanente en la sesión del día 13 de noviembre de 1923.

El argumento utilizado por la Comisión nos esclarece el problema planteado, pues mientras los descubiertos del contingente provincial eran absorbidos por una Diputación que disfrutaba de situación económica desahogada, eran posibles los aplazamientos y las moras de pago.

«pero surge la Ley de 1917, famosa y demoledora de las Haciendas del Sr. Alba, y la perturbación que ocasiona en la vida económica de todas las Corporaciones provinciales, produce en la nuestra una gran anormalidad por aumentar en forma caprichosa y extraordinaria las atenciones de la segunda enseñanza, de la Cárcel....» (45).

Al agravio político económico se unió un defecto procedimental por no realizar la Hacienda estatal liquidaciones previas, pero incluso el organismo central no comunicaba a las Corporaciones las cantidades que debían consignar en sus Presupuestos ordinarios para atender el pago de aquellas obligaciones impuestas, $y$, en consecuencia, tenían que arbitrar Presupuestos extraordinarios en que constasen las cantidades exactas adeudadas a la Hacienda central.

(44) Véase ADPLA. Comisión Permanente, sesión de 13 de noviembre de 1923, folio 93-4.

(45) Ibidem, folio 94.

REVISTA DE ESTUdIOS.-7 
Esta anormalidad administrativa, unida al hecho de que en 1914 el Ayuntamiento no cumplió sus obligaciones con la Diputación provincial, por lo que fue objeto de apremio y debido a la deteriorada situación económica de la Diputación desde 1917 sirvieron de fundamento para desestimar la reclamación, ya que renunciaba a realizar un reparto general de la deuda entre todos los Ayuntamientos por resultar manifiestamente injusto, y tampoco la Diputación podía ser objeto del apremio, pues en tal caso quedaría sin dotar, desatendidos y alterados los pagos de los

«Servicios de Beneficencia, Hospital, Manicomio y demás de carácter urgente que jamás han estado descuidados, sino más bien han sido y son actualmente el principal objetivo de esta Corporación provincial, como finalidad integra del bienestar de la Provincia» (46).

Con posterioridad al trámite del Presupuesto extraordinario se suscribió un Convenio con la Delegación provincial de Hacienda para pagar las deudas de la Corporación, correspondientes a 1923 al Tesoro, por los conceptos de Segunda Enseñanza y Cárcel, que ascendía a 105.944,42 pesetas, comprometiéndose la Diputación a pagar mensualmente 10.500 pesetas hasta amortizar la suma adecuada (47).

\section{B) La Hacienda desde el Estatuto provincial}

El Libro II del Estatuto provincial regulaba las Haciendas provinciales. De él se sentiría verdaderamente orgulloso su redactor, al conseguir sacar de la ruina a las Diputaciones, salvando las dificultades porque la cuestión no había sido apenas tratada en ningún proyecto anterior, pese a que en ella estaba la clave de la revitalización de las Corporaciones provinciales (48).

Aunque el contingente provincial fue reformado $y$ reducido según los casos en un 10 , un 20 y hasta un 30 por 100 , por lo que perdió su carácter de principal fuente de ingresos de los presupuestos provinciales, la facultad impositiva provincial fue reforzada al modificarse los arbitrios provinciales y aportarse un nuevo concepto: los impuestos y recursos cedidos por el Estado. En virtud del artículo 225 del Estatuto, las Diputaciones recibirían el 5 por 100 de las cuotas de la contribución territorial, y en la misma sección se encontraba atribuido a las Corporaciones provinciales la

(46) Ibídem, folio 94 vuelto.

(47) Ibídem, sesión del 23 de noviembre de 1923.

(48) Véase ORDUÑA REBOLLO, E.: Estudio preliminar legislación sobre Administración local, 1900-1975, vol. II, 1981, p. XXVIII. 
percepción del Impuesto de cédulas personales, que obligaba a todos los devengadores de rentas de trabajo desde una peseta anual en adelante $y$ a los contribuyentes por territorial, industrial $o$ minería, también a partir de una peseta anual.

Estas serían, sin duda, las fuentes de ingresos fijos más importantes, aunque también se preveía (arts. 228 y 229), que en caso de traspaso a las Diputaciones de Obras Públicas, establecimientos de Beneficiencia, Sanidad o Instrucción Pública, se dotaría en cada caso, por parte del Estado, el régimen de compensación económica correspondiente. Otros conceptos de interés fueron los recargos provinciales, entre ellos con carácter fijo, el 20 por 100 sobre las cuotas del impuesto de derechos reales y el 10 por 100 sobre el impueto de timbre. Se reconocía la posibilidad de establecer el 100 por 100 de recargo en los arbitrios municipales sobre solares sin edificar o terrenos incultos.

Finalmente, señalaremos dos aspectos que afectaron a la Diputación de Palencia directamente. El impuesto de cédulas personales entró en vigor en el ejercicio de 1926 (DT 8) y condonados íntegramente los débitos de las Diputaciones a favor del Estado por atenciones a Enseñanza e Instrucción Pública (DT 10), con lo que los Presupuestos de 1926 se ampliaron y resolverian un contencioso de graves transcendecias, como indicamos páginas antes.

Los Presupuestos de todas las Diputaciones, y entre ellos la palentina, tardaron un año en reflejar las modificaciones subsiguientes al Estatuto. No obstante, recordemos que en 1924 se habian incrementado $489.322,75$ pesetas, respecto al Presupuesto de 1923, y cuando se elabora el de 1925, figura sólo un aumento de 282.645,66 pesetas. A partir de 1926 las cifras llegarán a alcanzar cuantías considerables para la época (49).

\begin{tabular}{|c|c|}
\hline \multicolumn{2}{|c|}{$\begin{array}{c}\text { PRESUPUESTOS } \\
\text { DE INGRESOS Y GASTOS } \\
\text { AÑOS } 1925-1929\end{array}$} \\
\hline Años & Pesetas \\
\hline $\begin{array}{l}1926 \\
1927 \\
1928 \\
1929\end{array}$ & $\begin{array}{l}1.652 .546 .90 \\
2.001 .848 .72 \\
2.536 .957 .71 \\
2.253 .441,07\end{array}$ \\
\hline
\end{tabular}

(49) Datos procedentes de los Presupuestos publicados en los Boletines Oficiales de la Provincia anteriormente indicados y en liquidaciones del Presupuesto de 1927, libro de actas Comisión Provincial, 9/13 de enero de 1928, folios 4-3 y ss.; liquidaciones del Presupuesto 1928; ídem, 8/14 de enero de 1929, folios 3-3 y ss.; liquidaciones del Presupuesto de 1929 , ídem, $8 / 11$ de enero de 1930 , folios $1-3$ y ss. Elaboración propia. 
Para los años 1927, 1928 y 1929 disponemos de los datos referidos a los "Aumentos» incorporados a los respectivos Presupuestos:

\begin{tabular}{|c|c|c|c|}
\hline Años & Presupuesto & Aumento & $\begin{array}{c}\text { Presupuesto } \\
\text { Total }\end{array}$ \\
\hline $\begin{array}{l}1927 \\
1928 \\
1929\end{array}$ & $\begin{array}{l}2.001 .848,72 \\
2.536 .957,71 \\
2.353 .441,07\end{array}$ & $\begin{array}{r}58.320,19 \\
97.027,40 \\
979.678,61\end{array}$ & $\begin{array}{l}2.060 .168,91 \\
2.633 .985,18 \\
3.353 .119,68(50)\end{array}$ \\
\hline
\end{tabular}

La estructura del Presupuesto provincial se modificó completamente en 1925 y las Corporaciones provinciales elaboraron uno nuevo antes del 30 de junio y efectos del segundo semestre de dicho año. La normativa para su formación fue progresiva. Así, el modelado se publicó en el Boletín Oficial de la Provincia de 22 de mayo. El 13 del mismo mes, la Comisión Provincial conoció las instrucciones para establecer la imposición sobre la riqueza radicante en la provincia, cuyos acuerdos debían sancionarse por el Pleno antes de confeccionar el Presupuesto, hacer público el arbitrio y remitir al Ministerio el expediente y la ordenanza (51).

En este mismo contexto, situamos la carta-circular del director de Administración, comunicando a la Diputación palentina la cantidad a percibir por el concepto de recargo del impuesto de Derechos Reales y Timbre, que ascendía a 226.934 pesetas. Igualmente anunciaba que en breve se fijarían las cantidades correspondientes a caminos vecinales (52).

Para los arbitrios provinciales, se determinaban unos criterios provisionales de interpretación:

«a) Los arbitrios han de radicar siempre sobre la riqueza que se produce y no sobre la que se consume en una provincia, proveniendo de otra. b) Se debe huir de gravar la simple importación y exportación de cualquier clase de productos en una provincia porque este sistema generalizado nos llevaría a crear un verdadero laberinto de aduanas interprovinciales. c) Los gravámenes que recaigan sobre artículos de primera necesidad tropezarán siempre con criterios restrictivos por exigencias de la política de abastos» (53).

(50) Ibidem.

(51) Véase ibídem, sesión del día 13 de mayo de 1925, folio 11-3.

(52) Véase ibídem, sesión del día 25 de mayo de 1925, folio 13 vuelto.

(53) Véase ibídem, folios 13 vuelto y 13-3. 
Por último se refería a las aportaciones de las Corporaciones provinciales para reorganizar la jurisdicción contencioso-administrativa, correspondiendo a la Diputación de Palencia 20.000 pesetas (54).

Las instrucciones finales recibidas en los últimos días de junio suponían en realidad la continuidad hasta diciembre de 1925 del presupuesto en vigor, aprobado antes de promulgarse el Estatuto (55).

Entre las modificaciones que experimentó la Hacienda provincial en 1925 nos encontramos en el caso de Palencia, con un ejemplo de cesión de recursos municipales a la Diputación, motivado por el acuerdo del Ayuntamiento de Dueñas de 26 de agosto, que alcanzó: el 50 por 100 de cédulas personales; 20 por 100 de las cuotas de industrial; 20 por 100 de las de urbana; 32 por 100 del recargo municipal sobre contribución industrial; 16 por 100 del recargo municipal sobre la contribución rústica, urbana y pecuaria, que suponían 14.344 pesetas admitidas por la Comisión Provincial y rechazadas 2.219 pesetas, correspondientes al pago de atenciones de primera enseñanza, regulado por concierto de abonar 555 trimestrales, ya «que los atrasos no son objeto de las prescripciones del Estatuto» (56).

En julio de 1926 el panorama hacendístico de la Diputación Provincial había cambiado radicalmente. Así, en la liquidación del presupuesto del ejercicio de 1925-1926 el señor Benito Quiroga «consta(se) en acta el agrado con que la Permanente ha visto el lisonjero estado de la Hacienda provincial». Como muestra de tal prosperidad económica, en esa misma sesión se aprobó la liquidación al contratista que instaló la calefacción en el palacio provincial (57).

Las sombras se ciñeron a veces sobre el panorama económico de la Diputación, concretamente con los acuerdos del Congreso Municipalista de 1926, referidos al contingente del 2 por 100 de los presupuestos municipales o que se condonasen las deudas de los Ayuntamientos con la Diputación, hechos que merecieron la atención y oposición una y otra vez por parte de la Comisión Provincial Permanente de Palencia (58).

(54) Véase ibídem, folio 13-3.

(55) Véase ibídem, sesión del día 30 de junio de 1925, folio 23-4.

(56) Véase ibídem, sesión del día 7 de septiembre de 1925, folios 45-4 y 46.

(57) Véase ibídem, sesión del día 5 de julio de 1926, folio 77-3.

(58) Véase ibídem, sesión del día 11 de septiembre de 1926, folios 26 y 26 vuelto, y sesion del día 9 de octubre de 1926, folio 126 vuelto. 


\section{C) El Banco de Crédito Local}

El permanente endeudamiento de las Corporaciones Locales había creado en algunas una situación límite a principios de los años veinte, por cuya razón en los inicios de la dictadura se intentaron diversas medidas para resolverlo, algunas rigurosas pero sin el mayor éxito, pues la calamitosa situación de las Diputaciones no tendrían remedio hasta aprobarse el Estatuto provincial, que vitalizó las Haciendas provinciales.

Ante la necesidad de apelar al crédito para acometer obras de infraestructura y de servicios fue regulada la capacidad de endeudamiento de las Corporaciones Locales, y en el Reglamento de Hacienda Municipal de 23 de agosto de 1924, en su artículo 68, se encomendó al Gobierno realizar los estudios oportunos para crear un Banco de crédito comunal que, con el nombre de Banco de Crédito Local de España, se crearía casi un año después, al que, según Calvo Sotelo, el Estado no dispensó anticipo, aval ni franquicia de ningún género (59).

La Diputación de Palencia conoció su creación en la sesión del 24 de agosto de 1925, mediante una carta del director de la institución bancaria ofreciéndose a la Corporación para facilitar todos los antecedentes e informaciones precisas sobre operaciones financieras y resolver las consultas respecto a suscripciones, emisión de acciones, etc. (60).

A esta suscripción inicial, cuyo plazo acabó el 31 de diciembre de 1925, concurrió la Diputación Provincial de Palencia, que en el Pleno del día 26 de noviembre resolvió participar en la suscripción, fijando la Permanente en 10 el número de acciones, según el acuerdo que tomó dos días más tarde (61).

Las acciones tenían un valor nominal de 500 pesetas, de las que debían desembolsar el 25 por 100 del total antes del 28 de febrero de 1926, al objeto de percibir el beneficio íntegro que correspondiese para aquel ejercicio. La Comisión Provincial aprobó el desembolso de 1.250 pesetas para satisfacer el pago y autorizó al presidente para asistir a la reunión de accionistas que se celebró el 10 de marzo de 1926, al objeto de designar representantes de las Corporaciones Locales en el Consejo de Administración (62).

Sin más datos sobre la actividad del Banco de Crédito Local en Palencia, que al parecer no debió ser muy amplia en la provincia

(59) Véase Calvo Sotelo, J.: Mis servicios..., op. cit., p. 42.

(60) Véase ADPLA C. P., sesión del día 24 de agosto de 1925, folio 42-3.

(61) Véase ibídem, sesión del día 28 de noviembre de 1925, folio 72-4.

(62) Véase ibídem, sesión del día 10 de febrero de 1926, folio 20-3. 
durante el quinquenio 1925-1930, Calvo Sotelo señala que la distribución provincial de los contratos vigentes el 31 de diciembre de 1929 en Palencia eran dos por una cuantía de 64.000 pesetas, frente a los 32 contratos de Córdoba por 39.737.352,61 pesetas. Tomando como base dicha información, nos hemos permitido hacer un cuadro comparativo de la región para la referida fecha:

\begin{tabular}{l|r|r}
\hline \multicolumn{1}{c|}{ Provincias } & Contratos & \multicolumn{1}{c}{ Cuantias } \\
\hline Avila $\ldots \ldots \ldots \ldots \ldots \ldots \ldots$ & 13 & $5.494 .280,32$ \\
Burgos $\ldots \ldots \ldots \ldots \ldots \ldots$ & 1 & $1.800 .000,00$ \\
León $\ldots \ldots \ldots \ldots \ldots \ldots \ldots$ & 7 & $\mathbf{8 . 0 5 7 . 1 6 2 , 3 5}$ \\
Palencia $\ldots \ldots \ldots \ldots \ldots \ldots \ldots$ & 2 & $64.000,00$ \\
Salamanca $\ldots \ldots \ldots \ldots \ldots$ & 1 & $12.500,00$ \\
Segovia $\ldots \ldots \ldots \ldots \ldots \ldots$ & 7 & $1.083 .300,00$ \\
Soria $\ldots \ldots \ldots \ldots \ldots \ldots \ldots$ & 1 & $2.450 .000,00$ \\
Valladolid $\ldots \ldots \ldots \ldots \ldots$ & 3 & $1.880 .000,00$ \\
Zamora $\ldots \ldots \ldots \ldots \ldots \ldots$ & 4 & $2.472 .552,00$ \\
\hline
\end{tabular}

La cuantía más baja para todo el conjunto de las Diputaciones de régimen común la ofrecía Salamanca, y la más alta Sevilla, con 83.667.292,82 pesetas. Respecto a la región castellanoleonesa, los créditos eran inferiores a la media del país, situada en 10.206.618 pesetas por provincia, pues ninguna superaba tal cuantía (63).

No es aventurado justificar estas diferencias, en el caso de Sevilla, a los gastos y obras de la exposición. Mientras que en las provincias castellanoleonesas pesaría sin duda el temor a un endeudamiento preocupante y respecto de Palencia, quizá la razón se encuentre en una administración más austera y eficaz, que fue, como hemos podido detectar, objeto de diversas felicitaciones por su gestión y la observancia puntual de sus compromisos y débitos.

(63) Véase Calvo Sotelo, J.: Mis servicios..., op. cit., p. 43. 
REALA-1989, núm. 244. ORDUÑA REBOLLO, ENRIQUE. LA GESTION DE LA DIPUTACION DE PA...

REALA-1989, núm. 244. ORDUÑA REBOLLO, ENRIQUE. LA GESTION DE LA DIPUTACION DE:PA... 